\title{
Aberrant muscle bundle of the right ventricle
}

\author{
R. J. Barnes, K. H. Kwong, and Anthony C. S. Cheung \\ From the Medical Department, Hong Kong, and the Department of Surgery, University of \\ Hong Kong
}

Two cases of aberrant muscle bundle causing obstruction to right ventricular outflow are described. The relatively large number of cases collected by authors seems to indicate that the condition is more common than generally suspected. The fact that the aberrant muscle traverses the right ventricular cavity from the region of the crista supraventricularis to the lower part of the anterior wall of the right ventricle suggests that it takes its origin from the oblique component of the moderator band. Since two chambers in the right ventricle may be formed from a diaphragmatic type of infundibular stenosis, the term aberrant muscle bundle is preferred to two-chambered right ventricle. The need to separate this entity from other types of infundibular stenosis is emphasized because of the important surgical implications. The angiocardiographic features of this condition are examined and compared with selected cases of tetrad of Fallot. It is shown that filling defects low in the right ventricle may be present, and 'channels' traversing the aberrant muscle may be simulated, in cases of tetrad. Though these similarities exist, the diagnosis of aberrant muscle can often be made before operation.

In 196I, Tsifutis, Hartmann, and Arvidsson described a congenital cardiac anomaly which they called two-chambered right ventricle. Later the names double right ventricle, double-chambered right ventricle, aberrant muscle bundle, and anomalous muscle bundle, were applied to this entity (Tsifutis et al., I96I; Lucas et al., 1962; Hartmann et al., 1962: Hartmann, Goldring, and Carlsson, 1964; Coates, McClenathan, and Scott, 1964; Perloff, Ronan, and de Leon, 1965; Schlesinger, van Randwijk, and Chaillet, I965; Hudson, I965; Warden, Lucas, and Varco, 1966; Hindle, Engle, and Hagstrom, I968; Gale, Heimann, and Barlow, 1969). The anatomical distinction between aberrant muscle bundle and the other causes of infundibular stenosis have been noted by most of the authors, but there are differences in opinion as to the origin of the muscle bundle.

This paper describes 2 cases of aberrant muscle bundle causing right ventricular outflow obstruction, comments on the frequency of the anomaly, and discusses its anatomical structure. The right ventricular angiograms of aberrant muscle bundle and of tetrad of Fallot are examined in an endeavour to ascertain if these two conditions may be differentiated by this procedure.

Received I September 1970.

\section{Case reports}

Case I A youth, aged 19, noticed dyspnoea on exertion around the age of 8 , and cyanosis of the fingers and toes at 15 . His exercise tolerance decreased conspicuously in the recent 3 years. There was a history of squatting after exercise, but no syncope. Chest infections were frequent. The family history was not relevant. Physical examination revealed a small thin boy, $155 \mathrm{~cm}$ in height, body weight of $36 \mathrm{~kg}$. Central cyanosis was present, and there was clubbing of fingers and toes. The jugular venous pressure was not raised, and no giant ' $a$ ' wave was present. Pulse rate was 80 a minute, and blood pressure $120 / 80 \mathrm{mmHg}$. The apex beat was in the normal position; no thrill or parasternal lift was present. A pansystolic murmur, grade $3 / 4$, was heard maximally at the left sternal border at the level of the 3rd intercostal space. The second heart sound was single. Other systems were normal. The electrocardiogram showed an $R / S$ ratio of $I: I$ in $V_{I}$ and a dominant $R$ wave in $V_{3} R$ and $V_{4} R$. $T$ waves were inverted in the right praecordial leads. $X$-ray examination of the chest was within normal limits. Cardiac catheterization suggested the presence of a bidirectional shunt which was mainly from right to left; the findings are shown in Table $I$. The withdrawal tracing indicated the presence of an infundibular chamber (Fig. I). Right ventricular angiogram revealed a constant filling defect in both the anterior and the lateral views (Fig. 2). A large aberrant muscle bundle was found at operation attached to the crista supraventricularis at one end, and the anterior wall of the right ventricle on the other. Fig. 3 
TABLE I Cardiac catheterization findings

\begin{tabular}{|c|c|c|c|c|c|c|c|c|c|c|}
\hline \multicolumn{5}{|c|}{ Pressure $(\mathrm{mmHg})$} & \multicolumn{6}{|c|}{$\mathrm{O}_{2}$ saturation $(\%)$} \\
\hline $\begin{array}{l}\text { Case } \\
\text { No. }\end{array}$ & $\begin{array}{l}\text { Sex } 1 \\
\text { Age }\end{array}$ & $\begin{array}{l}R V \\
\text { proximal } \\
\text { chamber }\end{array}$ & $\begin{array}{l}R V \\
\text { distal } \\
\text { chamber }\end{array}$ & $\begin{array}{l}\text { Pulmonary } \\
\text { artery }\end{array}$ & $\begin{array}{l}\text { Vena } \\
\text { cavae }\end{array}$ & $\begin{array}{l}\text { Right } \\
\text { atrium }\end{array}$ & $\begin{array}{l}R V \\
\text { Proximal } \\
\text { chamber }\end{array}$ & $\begin{array}{l}\text { RV } \\
\text { Distal } \\
\text { chamber }\end{array}$ & $\begin{array}{l}\text { Pulmonary } \\
\text { artery }\end{array}$ & $\begin{array}{l}\text { Systemic } \\
\text { artery }\end{array}$ \\
\hline $\mathbf{I}$ & $M / 19$ & $120 / 4-10$ & $19 / 4-10$ & 19/10 & 63 & $62 \cdot 5$ & 63,81 & 66 & 66 & 85 \\
\hline 2 & $F / 12$ & $84 /-2+5$ & - & $5 / 2$ & 55 & 54 & 51 & - & 53 & 90 \\
\hline
\end{tabular}

shows the muscle bundle transsected. The whole of the aberrant muscle bundle traversing the right ventricular cavity was excised, and a ventricular septal defect, $1.5 \mathrm{~cm}$ in diameter, was repaired. The pulmonary valve and the rest of the outflow tract was normal. The patient had an uneventful recovery, and was discharged well.

Case 2 A girl of I I was cyanotic since the age of 3 , and had frequent episodes of chest infection. She admitted to squatting after exertion, and poor exercise tolerance. Family history was not relevant. Her height was $14 \mathrm{I} \mathrm{cm}$, body weight $21 \mathrm{~kg}$. Cyanosis and clubbing of fingers and toes were present. The jugular venous pressure was not raised. Blood pressure was $90 / 60 \mathrm{mmHg}$. The apex beat was on the 5 th intercostal space within the midclavicular line. A systolic thrill was present at the left sternal border at the level of the $3 \mathrm{rd}$ intercostal space. The associated systolic murmur was graded as $3 / 4$. The second heart sound was single, and other systems were normal. The electrocardiogram showed a dominant $R$ in $V I$ and V3R. $X$-ray film of the chest with barium swallow suggested a right-sided aortic arch. Cardiac catheterization findings were consistent with tetrad of Fallot, and the withdrawal tracing from the pulmonary artery to the right ventricle did not show an infundibular chamber. Table I shows the pressures and oxygen saturation at catheterization. The anterior and lateral views of the right ventricular angiogram show the aberrant muscle bundle during systole only (Fig. 4). The preoperative diagnosis was tetrad of Fallot, and the large filling defect was considered insignificant as it was not seen during diastole. At operation a large muscle bundle, obscuring the tricuspid valve and traversing the right ventricular cavity, was identified and excised. A ventricular septal defect, $1.5 \mathrm{~cm}$ in diameter, was closed by a Teflon patch. The patient made an uneventful recovery.

\section{Discussion}

Soon after the report of 7 cases of aberrant muscle bundle by Tsifutis et al. in 196I, 9 cases were reported by the same team in 1962 (Hartmann et al.). Lucas et al. in 1962 reported 6 cases. In the subsequent years, Coates et al. (1964) reported 4 cases; Hartmann et al. (1964), another 2 cases; Warden et al. (1966), I I cases; Girod et al. (1966), 2 necropsy cases; Hindle et al. (I968), 6 cases; and Gale et al. (1969) 5 cases. It should be observed that once this anomaly was recognized, the authors were able to collect a substantial number of cases; this probably indicates that it is not as uncommon as was previously supposed, and more cases may come to light with greater awareness of this entity. In our present series of 200 cases of congenital heart disease catheterized, 2 cases

FIG. I Withdrawal tracing of Case I, from the pulmonary artery to the right ventricle, showing the presence of an infundibular type of stenosis.

distal chamber of RV

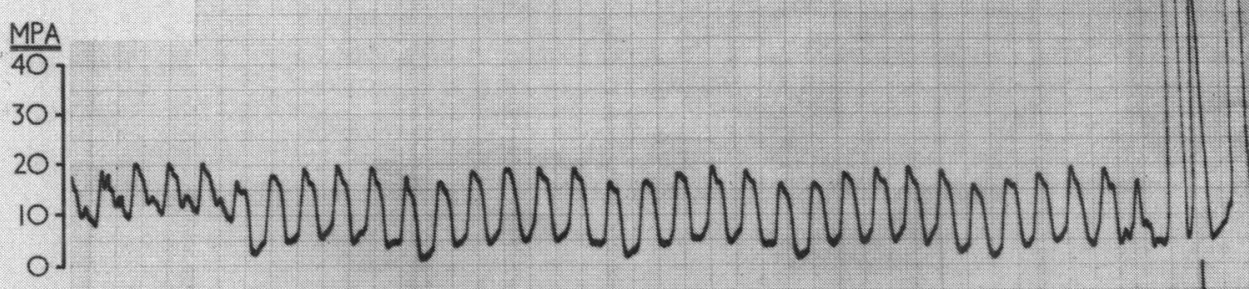


of aberrant muscle bundle were encountered. A third, recently diagnosed on the angiogram, awaits surgical confirmation.

The descriptive term two-chambered right ventricle, double right ventricle, and doublechambered right ventricle, indicates correctly the division of the right ventricle into two chambers; but certain cases of localized infundibular stenosis which gives rise to two chambers (Keith, 1909; Kjellberg et al., 1959; Watler and Wynter, I96I) should not be confused with aberrant muscle bundle (Tsifutis et al., 196I ; Hartmann et al., 1962; Lucas et al., 1962; Warden et al., 1966; Perloff et al., 1965; Schlesinger et al., 1965; Hindle et al., 1968). The infundibular stenosis of tetrad of Fallot is due to hypertrophy and abnormal direction of the parietal or septal band of the crista supraventricularis (Kjellberg et al., 1959); whereas in aberrant muscle bundle, 2 chambers are formed from an hypertrophied muscle band traversing the right ventricular cavity from the anterior wall, to the septum close to the attachment of the tricuspid valve, or to the middle of the crista supraventricularis (Lucas et al., 1962; Warden et al., I966; Hindle et al., 1968). The differentiation between other types of infundibular stenosis and that of aberrant muscle bundle is important because failure to recognize the latter may lead to misinterpretation of the site of a ventricular septal defect, and error in the surgical procedure (Lucas et al., 1962). The term aberrant muscle bundle emphasizes the anomaly which is particularly significant from the point of view of surgical correction.

We do not feel that aberrant muscle bundle should be classified as a variant of tetrad of Fallot because a ventricular septal defect may not be present (Tsifutis et al., I96I; Lucas et al., 1962; Hartmann et al., 1962; Coates et al., 1964; Warden et al., 1966), though in many cases the criteria of the tetrad would be satisfied (Cleland et al., 1969). Furthermore, aberrant muscle bundle associated with other congenital heart anomalies such as aortic stenosis, subaortic stenosis, mitral insufficiency, cor triatriatum, and some unusual anomalies have been described in infants (Hindle et al., 1968).

In 196r, Grant, Downey, and MacMahon described the presence of oblique fibres running from the region of the crista supraventricularis to form the major component of the moderator band. The authors indicated that hypertrophy of the oblique component of the moderator band could cause obstruction to blood flow. We feel that the aberrant muscle bundle probably originates from these fibres, since they cross the cavity from the
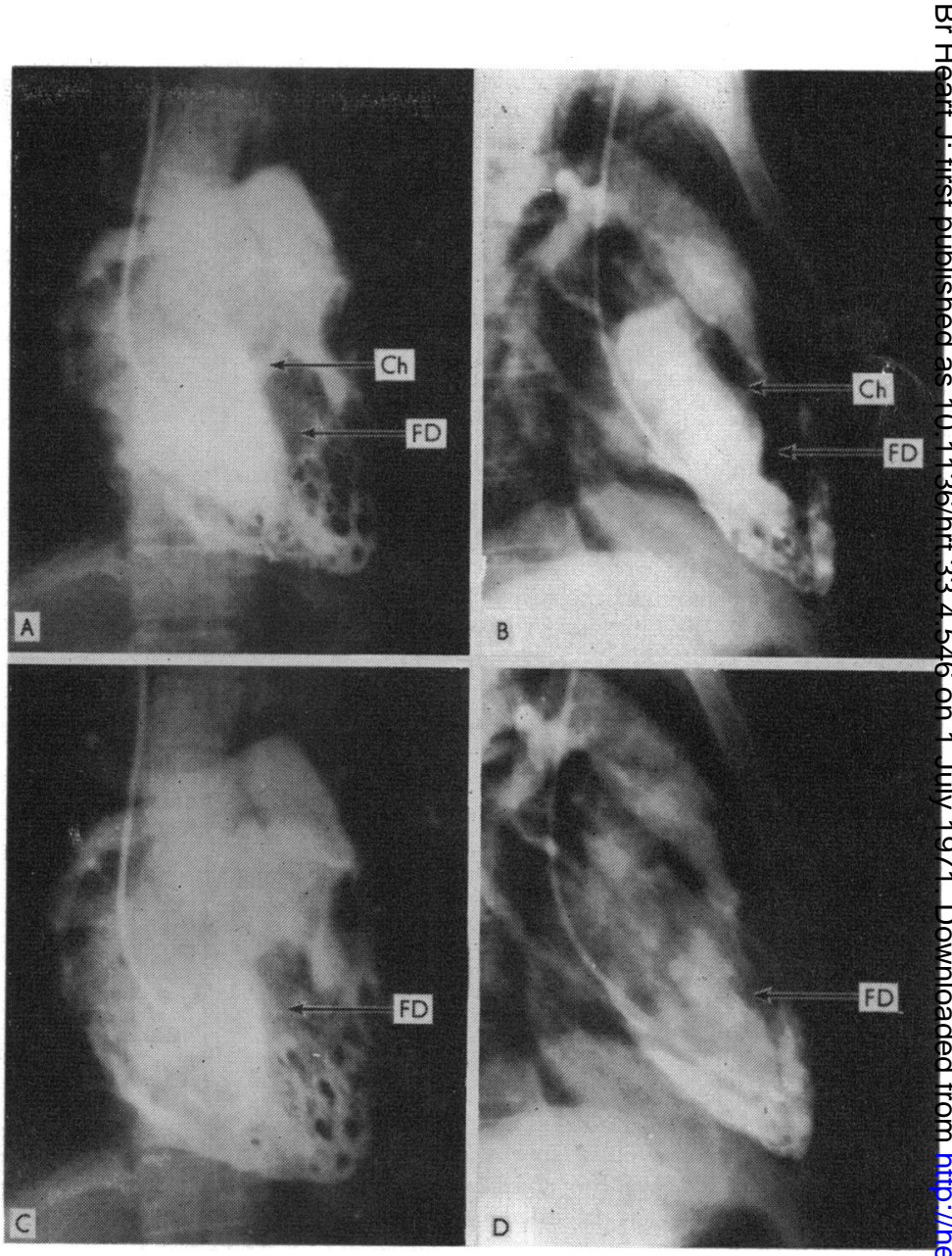

FIG. 2 Right ventricular angiogram of

Case I, upper two films showing the anterior

and lateral views in systole, the lower two in

diastole. A constant filling defect (FD) is seen

in both views; and in the lateral view it is

seen extending from the crista supraventricu-

laris to the anterior wall. $A$ channel $(C h)$

communicating between the proximal and

distal chambers is seen in systole.

crista to the anterior wall of the right ventricle.

Perloff et al. (1965) and Hindle et al. (1968) consider that the aberrant muscle is anomalous, and is not related to the oblique component. This may be true in certain instances where there is hypertrophy of the trabeculae of the right ventricle. It is conceivable that gross hypertrophy and involvement of other fibres may cause considerable distortion of the original anatomy. Lucas et al. (1962) and Warden et al. (1966) pointed out that the obstructing muscle bundle was not due to hypertrophy of the moderator band which is attached lower down in the septum than the 


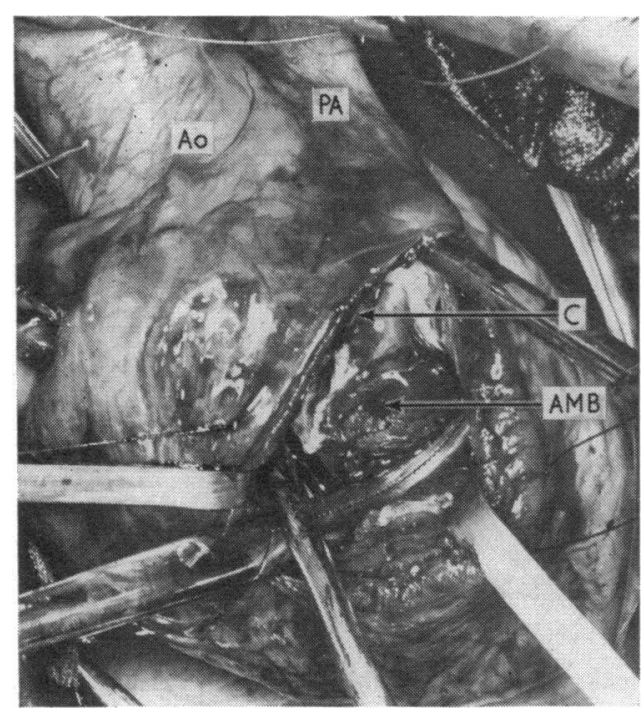

FIG. 3 The aberrant muscle bundle (AMB) of Case $I$ is seen transsected during operation. Its attachment to the crista $(C)$ is seen.

aberrant muscle bundle, and does not obstruct the outflow tract. Aberrant muscles giving rise to two chambers in the right ventricle without causing outflow obstruction have been described (Lucas et al., 1962; Lintermans et al., I968; Hindle et al., 1968). In some instances, the aberrant muscle bundle does not cause obstruction until a later stage when the hypertrophy reaches a critical stage (Hartmann et al., 1964). Gasul et al. (1957) described 3 patients with large ventricular septal defects, who later developed infundibular stenosis, and postulated that the latter was due to hypertrophy of the parietal and septal bands of the crista supraventricularis. This concept may be extended to include patients developing outflow obstruction from aberrant muscle bundle. Hypertrophy of the wall of the right ventricle in response to severe pulmonary valvular stenosis (Taylor, Bernstein, and Jose, 1964) is obviously distinct from aberrant muscle bundle.

Angiocardiographic diagnosis A summary of the diagnostic features of the angiocardiogram is shown in Table 2 . The most important criterion is the presence of a filling defect low in the right ventricle. A more reliable diagnosis can be made if the filling defect extends from the region of the crista to the ventricular wall in either the anterior or lateral views. Fig. 2 depicts these diagnostic features, and the persistence of the filling defect in all the films virtually confirms the diagnosis. The presence of a large filling defect during systole only, especially when seen only in the anterior view, is not reliable evidence of aberrant muscle bundle. Fig. 5 shows 4 cases of tetrad of Fallot, confirmed later by operation, which showed a large filling defect low in the right ventricle only in the anterior view, and in 3 cases only during systole. One case showed the filling defect in diastole as well.

Case 2 (Fig. 4) did not have definite angiographic evidence of aberrant muscle bundle

FIG. 4 Right ventricular angiogram of Case 2, upper two films showing the anterior and lateral views in systole, the lower two in diastole. A filling defect (FD) is seen in both views during systole, but not in diastole. In the anterior view, the filling defect extends from the crista supraventricularis downwards and laterally; the lateral views show only its attachment to the anterior wall.

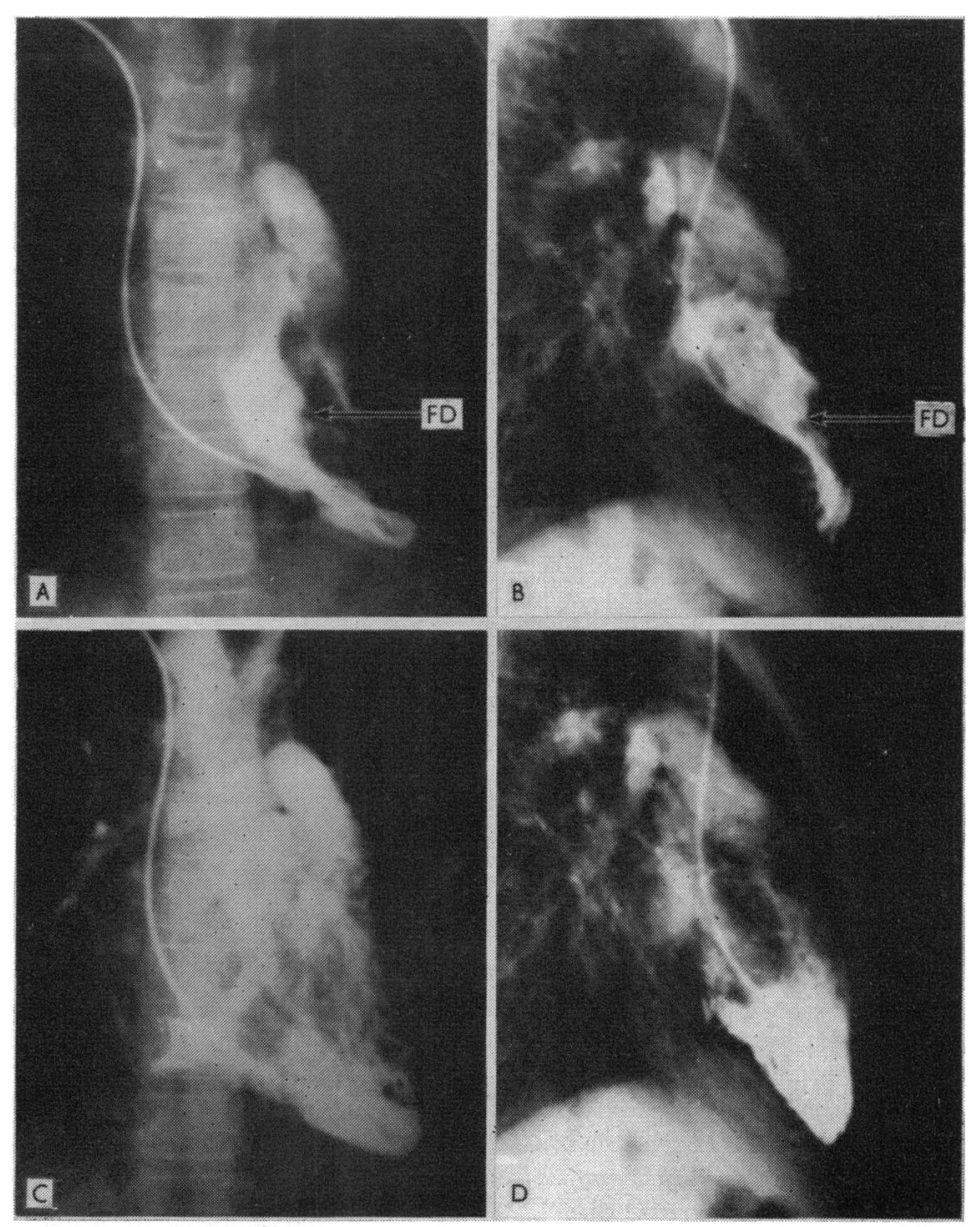


because a filling defect was visible in systole, and not in diastole. This patient was operated upon as a case of tetrad of Fallot, but in retrospect aberrant muscle bundle might have been suspected because the filling defect in the anterior view extended from the crista to the lower part of the right ventricle.

Channels, or routes of blood flow, traversing the aberrant bundle are frequently seen in angiocardiograms (Lucas et al., 1962; Coates et al., 1964; Warden et al., 1966; Gale et al., 1969). They are produced by contrast media flowing through slit-like apertures formed between the aberrant muscle bundle and the wall of the right ventricle (Lucas et al., I962; Warden et al., 1966). However, this finding is not pathognomonic, as it may be seen in cases of tetrad of Fallot (Fig. 4), and is possibly caused by trapping of contrast media by hypertrophied trabeculae of the wall of the right ventricle. We conclude that though evidence of aberrant muscle bundle may be seen in the right ventricular angiogram, false positives may occur. Ideally the surgeon should be forewarned of this condition, but it is not always possible to do so with certainty. It is fortunate that aberrant muscle bundle can be recognized at operation once the right ventricle is opened (Lucas et al., 1962; Coates et al., 1964; Warden et al., 1966).

We wish to thank the Director of Medical and Health Services of Hong Kong for permission to publish this paper.

\section{References}

Cleland, W. P., Goodwin, J., McDonald, L., and Ross, D. (1969). Medical and Surgical Cardiology. Blackwell Scientific Publications, Oxford and Edinburgh.

Coates, J. R., McClenathan, J. E., and Scott, L. P. (1964). The double-chambered right ventricle. A diagnostic and operative pitfall. American fournal of Cardiology, r4, 56r.

Gale, G. E., Heimann, K. W., and Barlow, J. B. (1969). Double-chambered right ventricle. A report of five cases. British Heart fournal, 31, 291.

Gasul, B. M., Dillon, R. F., Vrla, V., and Hait, G. (1957). Ventricular septal defects. Their natural transformation into those with infundibular stenosis or into the cyanotic or noncyanotic type of tetralogy of Fallot. Fournal of the American Medical Association, 164, 847.

FIG. 5 Four selected cases of tetrad of Fallot, $A, B, C$, and $D$, showing filling defects $(F D)$ low in the right ventricle during systole, simulating an aberrant muscle bundle. The filling defect in Case $A$ was also visible in diastole and in the lateral view. Channels (Ch) are present in $A, B$, and $C$, resembling those described in aberrant muscle bundle.
TABLE 2 Angiocardiographic diagnosis of aberrant muscle bundle

Angiocardiographic findings
Anterior view:
a) Filling defect in RV between outflow and
inflow tract
b) Filling defect is well below crista

\section{Lateral view:}

Filling defect in RV extending from crista supraventricularis to anterior wall near apex

\section{Constancy of filling defect:}

Constant in all subsequent films; or may be seen best, or only, during systole; or not seen at all

One or several channels, or routes of blood flow, may traverse obstruction

Authors
Lucas et al. (1962)
Hartmann et al. (1962)

Lucas et al. (1962)

Hartmann et al. (1962)

Lucas et al. (1962)

Hartmann et al. (1962)

Lucas et al. (1962)

Coates et al. (1964) Gale et al. (1969)
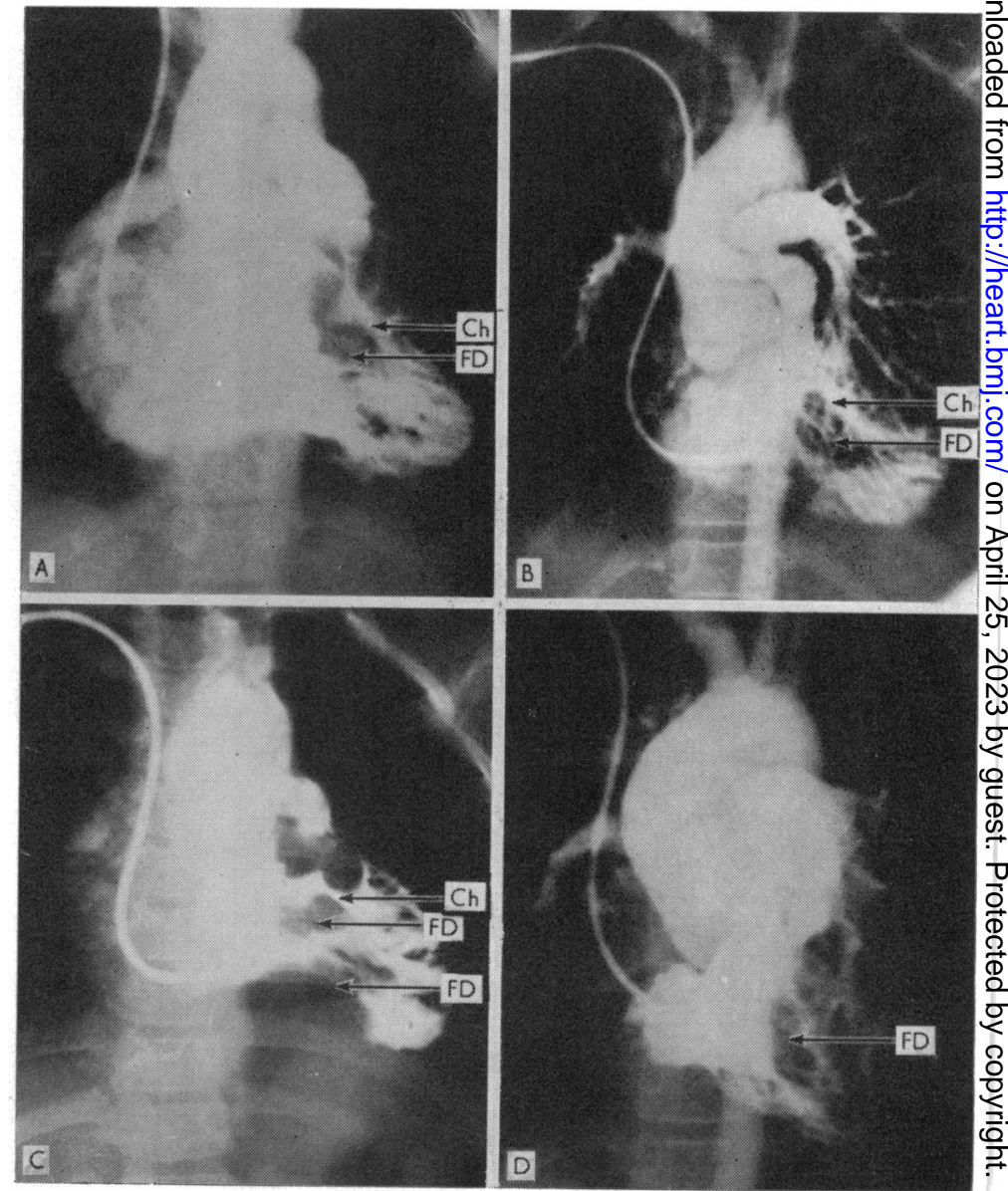
Girod, D. A., Raghib, G., Adams, P., Jr., Anderson, R. C., Wang, Y., and Edwards, J. E. (1966). Cardiac malformations associated with ventricular septal defect. American fournal of Cardiology, 17, 73.

Grant, R. P., Downey, F. M., and MacMahon, H. (I96I). The architecture of the right ventricular outflow tract in the normal human heart and in the presence of ventricular septal defects. Circulation, 24, 223.

Hartmann, A. F., Jr., Goldring, D., and Carlsson, E. (1964). Development of right ventricular obstruction by aberrant muscular bands. Circulation, 30, 679.

Hartmann, A. F., Jr., Tsifutis, A. A., Arvidsson, H., and Goldring, D. (1962). The two-chambered right ventricle. Report of nine cases. Circulation, 26, 279.

Hindle, W. V., Jr., Engle, M. A., and Hagstrom, J. W. C. (1968). Anomalous right ventricular muscles. A clinicopathologic study. American fournal of Cardiology, 21, 487.

Hudson, R. E. B. (1965). Cardiovascular Pathology, Vol. 2. Edward Arnold, London.

Keith, A. (1909). Malformations of the heart. Lancet, 2, 359.

Kjellberg, S. R., Mannheimer, E., Rudhe, U., and Jonsson, B. (1959). Diagnosis of Congenital Heart Disease, 2nd ed. Year Book Publishers, Chicago.
Lintermans, J. P., Roberts, D. B., Guntheroth, W. G., and Figley, M. M. (I968). Two-chambered right ventricle without outflow obstruction in ventricular septal defect. A case of spontaneous correction. American fournal of Cardiology, 21, 582.

Lucas, R. V., Jr., Varco, R. L., Lillehei, C. W., Adams, P., Jr., Anderson, R. C., and Edwards, J. E. (1962). Anomalous muscle bundle of the right ventricle. Hemodynamic consequences and surgical considerations. Circulation, 25, 443.

Perloff, J. K., Ronan, J. A., Jr., and de Leon, A. C. (1965). Ventricular septal defect with the 'twochambered right ventricle'. American fournal of Cardiology, 16, 894.

Schlesinger, F. G., van Randwijk, J., and Chaillet, J. L. (1965). Two-chambered right ventricle with interventricular septal defect. Cardiologia, 47, 256.

Taylor, R. R., Bernstein, L., and Jose, A. D. (1964). Obstructive phenomena in ventricular hypertrophy. British Heart fournal, 26, 193.

Tsifutis, A. A., Hartmann, A. F., Jr., and Arvidsson, H. (196I). Two-chambered right ventricle: report on seven patients (Abstract). Circulation, 24, I058.

Warden, H. E., Lucas, R. V., Jr., and Varco, R. L. (1966). Right ventricular obstruction resulting from anomalous muscle bundles. Fournal of Thoracic and Cardiovascular Surgery, 5I, 53.

Watler, D. C., and Wynter, L. (196I). Cor triventriculare: infundibular stenosis with subdivision of the right ventricle. British Heart fournal, 23, 599. 